\title{
Entre la Manzana Loca y el Greenwich Village. El surgimiento del rock contracultural en Buenos Aires
}

\section{Beteween Manzana Loca and Greenwich Village. The Rise of Countercultural Rock in Buenos Aires}

\author{
Ana Sánchez Trolliet \\ Becaria posdoctoral CONICET - Instituto de Altos Estudios Sociales, Universidad \\ Nacional de San Martín. Buenos Aires, Argentina. \\ absanchezt@gmail.com
}

\section{Resumen}

El artículo indaga en el despliegue del rock contracultural durante los años sesenta a partir de la circulación de ideas, objetos y personas entre Buenos Aires y Nueva York. Una serie de viajes emprendidos por artistas e intelectuales y el desarrollo de un argot original sirven de punto de partida para analizar cómo un sector de la juventud porteña tomó como propios la estética, las prácticas y el ideario contraculturales al interpretarlos como una cultura musical y urbana específica capaz de relevar al tango. Asimismo, se indaga en las expectativas que esto despertó entre distintos actores interesados por la cuestión juvenil. Se plantea que, en un contexto ideológico hegemonizado por una sensibilidad nacionalista y revolucionaria, la expansión del rock puso en tensión imágenes contrapuestas de Estados Unidos que contribuyeron a nacionalizar la interpretación de la cosmopolita cultura rock. Palabras clave: rock contracultural, cultura urbana, contactos culturales, antiimperialismo

\section{Abstract}

The article studies the evolution of countercultural rock during the sixties through the circulation of ideas, cultural goods and people between Buenos Aires and New York. A set of trips by artists and intellectuals, and the creation of an original slang are considered the starting point to discusss how a part of youth took as their own the counter-cultural aesthetics, practices and ideology. This youth interpreted counter-cultural rock as a new specific urban and musical culture that would replace tango. Moreover, this article examines the expectations that the countercultural rock aroused among different social actors interested by the juvenile question. It is argued that in an ideological context hegemonized by a nationalist and revolutionary sensitivity, the expansion of rock towards placed in tension opposite images of the United States that helped to nationalize the interpretation of rock culture.

Palabras clave: countercultural rock, urban culture, cultural contacts, antiimperialism. 
En 1969 [...] la ropa de los habitantes del East Village de Nueva York y del barrio Haight-Ashbury de San Francisco, comenzó a centellear en las zonas más dispares de Buenos Aires: desde La Manzana Loca hasta Flores, Caballito o Morón. ¿Pero existen en Buenos Aires los hippies? ¿Se repiten las costumbres de los subterráneos norteamericanos? [...] ¿Cuántos de los centenares de personas que concurren a los conciertos de música beat, ataviados con la ortodoxa vestimenta hippie, repiten realmente la experiencia norteamericana? Es probable que ninguna. Curiosamente, pese a que día a día aumenta la cantidad de adolescentes que se dejan crecer lánguidas cabelleras y se enfundan en centelleantes camisas, resulta casi imposible suponer que el fenómeno se reproduzca en forma auténtica en Argentina.

“Cómo viven los hippies argentinos?”. Panorama, 15 de diciembre, 1969.

A fines de la década del sesenta, los habitantes de Buenos Aires se habían familiarizado con el estilo de vida de los hippies. Los diarios y las revistas locales, que habían estado ofreciendo recurrentes crónicas sobre lo que consideraban las excéntricas costumbres de los jóvenes norteamericanos, comenzaron a prestar atención a la versión local de quienes preferían hacerse llamar "náufragos". Los hippies porteños habían tomado su nombre de la canción "La Balsa”, popularizada por el conjunto Los Gatos, después de que fuera editada en 1967 por la filial argentina de la discográfica norteamericana RCA. La canción alentaba a construir una balsa para "naufragar" y "partir hacia la locura", y no tardó en convertirse en un himno generacional que se posicionaba en forma crítica frente al proyecto cultural conservador del recién inaugurado gobierno militar de la "Revolución Argentina".

En sus tierras de origen, lo hippie aludía a una multiplicidad de fenómenos expresados en el arte, la música, la filosofía, la literatura, la moda, en convocantes congregaciones en el espacio público y en la vida política. En Buenos Aires, el término quedó asociado con quienes escuchaban y asistían a los conciertos de música beat, aunque esto no excluyera la adopción de una sensibilidad más englobante que se manifestaba también en sus ideas, su lenguaje y sus hábitos.

Los hippies porteños habían surgido hacia 1965. Eran un pequeño grupo de jóvenes músicos y poetas de clase media, principalmente varones, que se veían a sí mismos como unos "divertidos conspiradores de la sociedad" que proponían "vivir sin dormir hasta romper las barreras de la rutina mental" (de Zer 44). Sus "naufragios" habían tomado la forma de derivas urbanas musicalizadas que, estimuladas muchas veces con anfetaminas, se extendían por las calles de Buenos Aires durante días y noches interminables. Con estas andanzas urbanas, los jóvenes rockeros propusieron 
nuevas formas de ocupación de la ciudad y un nuevo estilo de organización de la vida cotidiana a través de los cuales cuestionaron los mandatos familiares y la moral dominante de las clases medias urbanas.

Pero hacia el fin de la década, el reducido circuito local del hippismo ya se había convertido en un extendido fenómeno social y comercial, como podía observarse en las largas colas de chicos y chicas adolescentes en las puertas de los reconocidos teatros de la Avenida Corrientes y el Instituto Di Tella (IDT), el más vanguardista centro de las artes de la ciudad. Además, como se menciona en el epígrafe que recupera una crónica publicada en el difundido semanario Panorama, los náufragos ya no solo tenían su punto de reunión en las zonas de la élite artística e intelectual de Buenos Aires - la llamada "manzana loca"-, sino que también se habían extendido hacia los menos cosmopolitas y letrados paisajes del suburbio bonaerense.

Aunque las comparaciones con el contemporáneo fenómeno norteamericano resultaran ineludibles, quienes se identificaban con el estilo de vida de los "náufragos" se negaban a ser considerados como una mera imitación. El ideario hippie los hacía sentir partícipes de un idioma juvenil trasnacional, pero eso no significaba que renunciaran a una búsqueda de autenticidad. En relación con esto, no es casual que los estudios dedicados a analizar el surgimiento del rock y la contracultura en Latinoamérica y, en Argentina en particular, se hayan preguntado con frecuencia por el modo en que se tensionaron y articularon las idiosincrasias nacionales con los imaginarios transnacionales promovidos por una cultura que encontraba en el cosmopolitismo y la transculturación un valor fundamental (Schanton 41-56). Por ello, los trabajos centrados en indagar a las emergentes escenas rock latinoamericanas, aunque conscientes de los procesos de mezcla e hibridización enmarcados en lo que se ha llamado la "contracultura global" (Zolov, "Introduction" 357), han tendido a hacer hincapié en los procesos que contribuyeron a su nacionalización, priorizando en sus análisis las particularidades que permitieron a sus congéneres interpretar al rock como un fenómeno "nacional" (Alabarces y Varela; Cepeda Sánchez; Dunn; Flachsland; Manzano, The age of youth; Pacini Hernández et al., Zolov Refried Elvies).

Sin embargo, esta perspectiva nacionalista ha tendido a obliterar la importancia de la dimensión urbana en la cultura rock como también la circulación internacional de ideas, objetos y personas que este género musical impulsó entre las ciudades latinoamericanas y las norteamericanas. En cuanto a la dimensión urbana, se trata de una cuestión fundamental no solo para la imaginación de un género musical que se autopercibe como el sonido de la ciudad moderna (Gillet 25) sino que también para los requerimientos de su circulación y su difusión. En el caso de Buenos Aires, esta identificación con la ciudad resulta especialmente sugerente porque para sus promotores el rock estaba llamado a relevar generacionalmente al tango en la tarea de darle identidad musical a Buenos Aires (Sánchez Trolliet 517-36). Así, mientras que las típicas evocaciones tangueras al empedrado, el farolito, las costureras o los taitas remitían a una recuperación nostálgica de un lejano pasado urbano, las can- 
ciones rockeras expresaban los sentimientos de unos jóvenes inconformistas ante la "metrópolis arrolladora" (Grinberg 71). A través de las canciones y de la creación de un argot particular, los rockeros pretendieron ofrecer un fresco sonoro del espacio metropolitano contemporáneo en el que las reminiscencias sonoras internacionales se conjugaban con una ciudad que pretendía ser moderna, cosmopolita y estar conectada con el mundo a través de su cultura (Podalsky 22). Por ello, antes que un impedimento, el origen "importado" del rock potenciaba las posibilidades de consolidar las bases de una nueva, duradera y "auténtica" identidad musical para Buenos Aires y sus jóvenes contraculturales.

En cuanto a la circulación internacional de ideas, objetos y personas, este artículo considera los primeros años del rock contracultural porteño como una cultura urbana en tránsito entre Buenos Aires y Nueva York. Si bien otras escenas urbanas y musicales - como Londres-fueron inspiradoras para los promotores del rock local, Nueva York pareció atraerles como ninguna otra. Es por esto que el despliegue del fenómeno hippie, el rock y la contracultura en Buenos Aires deben ser puestos en relación con una serie de visiones sobre Estados Unidos que encontraron allí un territorio inspirador para el desarrollo de prácticas artísticas y renovados debates intelectuales.

El temprano interés que algunos jóvenes tuvieron por la contracultura supuso la llegada a Buenos Aires de las ideas vinculadas con la nueva izquierda norteamericana, como el ecologismo, los movimientos de reivindicación de los negros y aborígenes, la vida en comunidad, la recuperación de las filosofías orientales, el antibelicismo, la prensa subterránea, así como también el interés por prácticas artísticas como la psicodelia, la literatura beatnik y el arte pop. Esto implicó, con frecuencia, viajes de artistas, de escritores y gestores culturales hacia Estados Unidos, la edición local de discos con compilaciones de canciones y la publicación de libros y traducciones donde periodistas y académicos interpretaban los nuevos estilos de vida de los jóvenes urbanos norteamericanos.

Tal imaginación positiva sobre Estados Unidos coincidía con el desplazamiento que se había producido desde las metrópolis europeas a las norteamericanas como centros hegemónicos de referencia para las artes, la cultura y las ciencias sociales (Blanco, King, Petrus y Cohen). Los programas norteamericanos de apoyo al arte y la creación de proyectos museográficos renovadores, por un lado, junto con la emigración de intelectuales europeos hacia Nueva York durante la Segunda Guerra Mundial, por el otro, ubicaron simbólicamente a esta ciudad como una efervescente usina de la vanguardia que en los años sesenta encontraría en el arte pop y el rock psicodélico a sus agitadores más destacados.

En cambio, la crítica a las políticas expansivas norteamericanas predominante en aquella época entre buena parte de la élite cultural de izquierda local tendió a condicionar las investigaciones posteriores que se emprendieron sobre aquellos años. Es por esto que gran parte de los trabajos concentrados en la cultura argentina de 
los años sesenta en relación con Estados Unidos prestó más atención a los discursos antiimperialistas, a las distintas formas en las que se "americanizó" la cultura local o bien en la influencia de instituciones asociadas con programas de intervención estatal, que proliferaban al compás de la Guerra Fría y la Alianza para el Progreso (Barbero y Regalsky; Cohn; Georgieff; Gorelik, "Miradas cruzadas"; Mudrovcic; Pratt; Terán).

En este marco, Eric Zolov ha señalado para el caso mexicano que el desarrollo del rock no puede desentenderse de los debates en torno al imperialismo. Los músicos y los seguidores de este género musical tuvieron que lidiar con las impugnaciones que otros pares generacionales propinaban contra ellos al identificarlos como "agentes extranjerizantes”. Por otra parte, el éxito de esta música y sus posibilidades de reproducción estuvo apuntalado en gran medida por los desarrollos tecnológicos y por las industrias discográficas norteamericanas-CBS, RCA, entre otras-. Y también porque la vertiginosa expansión del rock, la contracultura y el hippismo por todo el globo terráqueo contribuyó a forjar una imagen de Estados Unidos entre las jóvenes generaciones que, como bien lo advirtieron los miembros del Servicio de Información Norteamericano, contenían un alto potencial positivo si eran reinterpretados como parte de un proyecto político ajustado al "mundo libre" y a los principios democráticos (Refried Elvis 234-47).

Este artículo busca indagar en el impacto que generó el interés de los jóvenes contraculturales por el mundo norteamericano en un contexto caracterizado por una intensa politización juvenil alineada con consignas revolucionarias tercermundistas, así como también en el modo en que sus críticas condicionaron las posibilidades de reconocimiento artístico y cultural del rock entre los sectores juveniles militantes. Si bien los jóvenes contraculturales mantuvieron distancia con la radicalización política a la que despertaron amplios sectores de la juventud interpelados por la Revolución Cubana y las luchas por la liberación del Tercer Mundo, no fueron impermeables a su sensibilidad nacionalista y revolucionaria. En las páginas que siguen se verá cómo estas retóricas, junto con el fuerte rechazo al expansionismo norteamericano que circulaba entre los jóvenes radicalizados, impulsó a los rockeros a una paradójica búsqueda por lo "nacional" que no había sido imaginada en sus primeros tiempos.

Este artículo está dividido en tres partes. En la primera, se describen una serie de viajes emprendidos entre 1964 y 1970 desde Buenos Aires hacia Nueva York por escritores y artistas que, a su regreso, pusieron en marcha diversas actividades, las cuales contribuyeron a difundir la música rock y el ideario de la contracultura en el contexto local. En la segunda parte, analizo las polémicas que algunos músicos y su público entablaron en torno al uso del inglés y del castellano como idiomas "legítimos" del rock. En la tercera y última parte, me detengo en las interpretaciones que otros actores preocupados por la cuestión juvenil, en especial las organizaciones políticas de izquierda, tuvieron acerca del rock contracultural como una práctica "extranjerizante" y "proimperialista". 


\section{“¿Quién es Bob Dylan?”}

Esto pregunta un joven asombrado, en una escena de Tiro de Gracia (Ricardo Becher, 1969) - película que retrata la vida de la vanguardia porteña en los años sesenta-, cuando otros amigos le piden que el próximo disco que está por poner en una fonola sea uno de Bob Dylan y no otro más de tango. Como sugiere esta secuencia, la información que se disponía en Buenos Aires sobre el incipiente mundo de la contracultura, los hippies y las nuevas cadencias musicales que electrificaban al folk norteamericano era escasa y transitaba por estrechos circuitos culturales. Además, la imagen del rock como una forma de expresión de la rebeldía juvenil que había sido difundida por películas norteamericanas como Blackboard Jungle o Clock around the rock a mediados de los años cincuenta, habían sido trocadas por una "domesticación" de este género musical. Por ello, el rock en la Buenos Aires de los tempranos sesenta todavía permanecía asociado, para buena parte de la sociedad, con los mediáticos conjuntos "nuevaoleros" del Club del Clan y la Escala Musical que proponían un estilo de entretenimiento musical televisable y apto para compartir en familia (Manzano, "Ha llegado la nueva ola" 39).

Por otra parte, si bien el alcance global de la música rock en sus versiones "rebeldes" no puede dejar de ser pensado en relación con las redes de comercialización y distribución que pusieron en marcha las industrias culturales (Frank), su recepción en el escenario argentino, especialmente en el porteño, estuvo lejos de haber sido apuntalado por ellas en sus primeros pasos. Por el contrario, quienes se consagrarían como los pioneros del también llamado "rock progresivo" en Argentina (Manal, Moris, Almendra, Los Gatos, Vox Dei, Los Abuelos de la Nada, etcétera) coinciden en diagnosticar a la Buenos Aires de mediados de los sesenta como un territorio poco fértil para hacer anclar esta música electrificada y las iconoclastas versiones de la contracultura. Como han demostrado los trabajos de Adamovsky y Garguin, la clásica imagen que persistía entre amplios sectores sociales durante el primer lustro de la década del sesenta sobre la excepcionalidad de Argentina como un país sin conflictos sociales ni étnicos profundos, hacía dudar sobre las posibilidades de difusión de un género musical que se inspiraba en las luchas y demandas por la integración racial y el pacifismo.

En este marco, la posibilidad de acceder a las novedades musicales internacionales constituía toda una hazaña pues los nuevos discos tardaban en llegar a Buenos Aires y, cuando lo hacían, sus precios resultaban onerosos incluso para los jóvenes de clase media (Delgado 28). Por ello los discos solían ser traídos por quienes viajaban a Estados Unidos o Europa, y esta escasez material derivaba en una práctica colectiva que contribuía a la educación del gusto musical y a la conformación de una identidad grupal en torno a la escucha musical. Claudio Gabis, quien se consagró como guitarrista de Manal, recuerda las dificultades que tuvo durante sus últimos años como estudiante en el colegio secundario para acceder a los discos de Bob Dylan que había 
descubierto a través de Hit Parader, una revista de crítica musical norteamericana que compraba en un kiosco de diarios cercano al IDT. Discos como The Freewheelin' editado en 1963 y Highway 61 Revisited de 1965, resultaban imposibles de conseguir en las disquerías porteñas. Entonces, Gabis se comunicó con la subsidiaria en Buenos Aires de la discográfica cBs que había editado estos discos en Estados Unidos y consiguió una entrevista personal con el director del Departamento de Música Internacional. La reunión resultó positiva, Gabis volvió a su casa con los dos discos anhelados y jamás le pidieron que los regresara porque -según su recuerdo- en CBS estaban seguros que Bob Dylan nunca se editaría en Argentina (Gabis).

Los artistas que promovieron el despliegue del rock contracultural local transitaron durante sus primeros años por fuera del mercado discográfico y encontraron en el circuito cultural de la vanguardia en la ciudad de Buenos Aires una inmejorable plataforma de intercambio, encuentro y divulgación. Este itinerario cultural se emplazaba en el corazón comercial y administrativo de la ciudad en torno al casco histórico y su área de influencia. Desde distintos barrios, intelectuales y artistas se acercaban a las pocas manzanas donde se congregaban las librerías, galerías de arte, bares, pequeños teatros y salas de cine-arte que se colaban entre los edificios de gobierno, las salas de espectáculo comerciales y las torres de oficinas cuyas construcciones se multiplicaban. Este circuito, que no había cambiado su localización desde principios de siglo, había cobrado un nuevo impulso luego de que en 1958 se crearan en la Facultad de Filosofía y Letras de la Universidad de Buenos Aires las novedosas carreras de Sociología y Psicología y, en 1963, se instalara el multifacético Centro de Artes del Instituto Di Tella dependiente de la pujante automotriz Siam-Di Tella y financiado, en parte, con fondos de la Rockefeller Foundation (Gorelik, "Buenos Aires. La ciudad y la villa” 332-37; King 169; Sánchez Trolliet, "Buenos Aires Beat" 527). Si bien la facultad mudó su sede al poco tiempo, ambas instituciones aportaron a esta zona unos renovados aires culturales que derramaban un espíritu de modernidad y simultaneidad con el mundo.

Fue en estos mismos bares, convertidos en centros de redacción de revistas literarias, donde los ideales de la contracultura comenzaron a transitar. En Eco Contemporáneo, Opium, Piumo y Sunda, escritores locales transmitieron y tomaron como propios los postulados de los poetas "santos" de la generación beat. La asociación de este movimiento cultural con la música llegaría poco después, sobre todo, a partir del viaje que algunos intelectuales y artistas emprendieron hacia Estados Unidos desde 1964.

Nueva York fue la ciudad más evocada entre quienes se identificaban con la contracultura y las renovaciones musicales de los años sesenta. Fue, en particular, la activa vida artística y literaria que se desarrollaba en el lower Manhattan en torno al Washington Square Park y los coffeshops que lo rodeaban, lo que más atrajo la atención de los viajeros argentinos. La tradición bohemia del Greenwich Village, que se remonta a principios del siglo veinte con sus reuniones de anarquistas y surrealistas, 
había cobrado un nuevo ímpetu en la década del cincuenta. Los inmigrantes italianos de clase media baja que habitaban el barrio comenzaron a ver cómo sus calles se poblaban de "marginales" provenientes de las clases medias y altas que rechazaban vivir en los suburbios urbanos impugnados por haberse convertido en la cristalización del conformismo de la segunda posguerra (Medovoi 91-135). Los nihilistas poetas beat y los expresionistas abstractos alquilaron departamentos baratos en los edificios cercanos a la zona portuaria del Village, convirtieron a sus hogares en talleres de arte y centros de reunión. Los músicos de jazz y folk hicieron del Washington Square Park un escenario de participación cívica y congregación racial que, de la mano de Bob Dylan, dio inicio a las primeras versiones electrificadas del folk. Mientras tanto, muchos de sus vecinos, guiados por Jane Jacobs, se organizaban para reivindicar la vida en la calle e impedir los avances de la moderna planificación urbana impulsada por Robert Moses, al tiempo que el semanario barrial Village Voice, se iba convirtiendo en un pionero de la prensa subterránea que daba voz a los jóvenes hippies y psicodélicos, como Jimi Hendrix, quien también se acercó al barrio (Berman 338; Petrus y Cohen 104-145; Strausbaugh 433-445).

Uno de los primeros argentinos en conocer estas experiencias fue Miguel Grinberg, quien luego de asistir a un festival de poesía que coorganizó en la Ciudad de México en 1964, visitó el sur de Estados Unidos, San Francisco y Nueva York, donde permaneció por tres meses viviendo en las cercanías del Village (Memoria 14). Grinberg había sido una de las primeras figuras en publicar los poemas de la generación beat y los tópicos de la contracultura. ${ }^{1}$ Su revista Eco Contemporáneo (1961-1969), editada junto con el escritor Antonio Dal Masetto y el estudiante de filosofía Juan Carlos de Brasi, tradujo los escritos de la Beat Generation y registró el intercambio epistolar que desde 1959 Grinberg había mantenido con Allen Ginsberg, Henry Miller, Lawrence Ferlinghetti, Jack Kerouac y otros poetas de este movimiento.

Aunque se tratara de una revista literaria, sus páginas no omitían la crítica cultural en una estela de pensamiento que se postulaba contestataria, crítica del marxismo y ajena a instituciones partidarias. Eco Contemporáneo tenía una explícita preferencia por la cultura alternativa norteamericana y, si bien se incluían notas sobre el estructuralismo y el neorrealismo, su programa editorial promulgaba la formación de un americanismo de nuevo tipo que incluía a Estados Unidos en oposición a lo que describía como la vetusta cultura europea.

$\mathrm{Al}$ regreso del viaje, las crónicas sobre las experiencias contestatarias norteamericanas se volvieron cada vez más recurrentes. A partir del número 8-9 de 1965 se comenzaron a publicar artículos sobre las acciones de los hippies, transcripciones de artículos de Malcom X y Stockely Carmichael, críticas a la carrera armamentista

1 Otra figura que desde la literatura incorporó tempranamente a la cultura beatnik fue Alberto Vanasco, sobre su viaje a Estados Unidos y su obra Nueva York, Nueva York (Viñas 299-309). 
norteamericana y referencias a The Beatles y Bob Dylan. En las memorias sobre su viaje a Nueva York, Grinberg confiesa haber escuchado allí a The Beatles por primera vez:

Me senté para almorzar ante el mostrador de la cafetería de la terminal y de pronto alguien puso unas monedas en el tocadiscos automático (jukebox) del lugar [...]: Please please me, I saw her standing there, She loves you. [...]. Nunca había escuchado antes algo así. The Beatles. Ese mismo día hacían la tercera presentación televisiva de su debut en los Estados Unidos, según un diario que compré de inmediato. [...]. El contacto sonoro me produjo una intensa taquicardia. Allí sucedía algo que impactaba la sensibilidad, sin filtros. Lo viví como una señal de bienvenida a un nuevo mundo [...]. La beatlemanía iniciaba en esas horas su ciclo de conquista mundial (12).

Estas melodías estimularon tanto a Grinberg que a su regreso se acercó a la incipiente escena rock local y se convirtió en uno de sus más activos difusores. A fines de 1966 organizó un recital en un pequeño teatro donde se presentaron los músicos Mauricio "Moris" Birabent, Alberto “Tanguito" Iglesias, Alejandro Medina y Facundo Cabral (Kreimer 21). La sala estaba ubicada en el Abasto, el tradicional barrio del tango. Esta elección no fue azarosa, como recuerda Grinberg, "busqué un lugar porteño mítico: el Abasto, pensando que lo nuestro era histórico y tenía que ser en territorio de Carlos Gardel” (Grinberg, La generación V 126). Por otra parte, las reducidas dimensiones del teatro - no cabían más de cien personas- se correspondían con el intento de estos artistas por convertir a su música en una forma cultural “alta”. El teatro y sus butacas que imponían silencio y contemplación, se planteaban como un tipo de espectáculo contrario al de los bailes de fin de semana en los populares clubes sociales de barrio donde se ofrecía música juvenil en vivo de géneros variados -tango, twist, canción melódica, "nueva ola" y grupos que se multiplicaban al compás de la "beatlemanía"(Pujol, La historia del baile 273). Este encuentro inició una larga y continua saga de actividades que vincularon a Miguel Grinberg con la escena rockera local a través de su participación en distintos medios de comunicación. ${ }^{2}$

Claudio Gabis fue otro activo difusor de las renovaciones musicales norteamericanas. En 1966 viajó junto a sus padres a Nueva York mientras cursaba sus estudios secundarios. Este viaje le permitió hacerse de una discoteca con una gran cantidad de ejemplares imposibles de conseguir en el país: trajo discos de Jefferson Airplane, Bob Dylan, Janis Joplin, Country Joe \& the Fish y grabaciones de blues como las de

2 Miguel Grinberg tuvo una larga trayectoria como difusor de las actividades y las ideas del rock, entre ellas se cuentan sus críticas de discos y recitales en reconocidos medios gráficos de los años sesenta como el semanario Panorama y Primera Plana; en la década del setenta, el diario La Opinión y, en los ochenta, en Tiempo Argentino. También condujo por radio Municipal el programa radial El son progresivo dedicado exclusivamente al género rock; organizó encuentros multiartísticos en el Parque Centenario y editó múltiples revistas alternativas de considerable circulación entre las que se destacan Contracultura (1970) y Mutantia (1980-1985). 
Paul Butterfield Blues Band, Muddy Waters, вв King, Big Bill Broonzy, Robert Johnson, entre otros (Cocaro). Refiriéndose a la novedad que suponía su discoteca en Buenos Aires, Claudio Gabis recuerda que "era imposible" tenerla aquí, "nadie estaba interesado en eso, porque no lo conocían y porque, por otra parte, era caro" (Gabis).

A raíz del viaje, Gabis inició un proceso de investigación sobre la renovación musical norteamericana y, si bien se interesó por la música británica como The Beatles y The Rolling Stones, su principal interés estuvo en Bob Dylan, en la música negra norteamericana y, en especial, en el blues. Esta nueva discoteca le sirvió como "pasaporte" para ingresar en el ambiente de los músicos, artistas y algunos jóvenes intelectuales nucleados en torno al Instituto Di Tella. Por otra parte, sus compañeros de colegio Daniel Samoilovich y Jaime Potenze que "formaban parte de la élite de intelectuales intocables del Colegio Nacional Buenos Aires", lo convocaron para escribir un artículo sobre la canción de protesta, el rock psicodélico y los movimientos de lucha civiles en el primer número de una revista editada por ellos, Diguem No, en septiembre de 1966 (Gabis, "Nuevo folklore norteamericano" 3-6).

Tal voluntad de dar a conocer estas nuevas corrientes musicales se continuó en unas charlas que, con el auspicio de la embajada norteamericana, organizó al año siguiente en la Asociación de Ex Alumnos del Colegio Nacional Buenos Aires. Por otra parte, antes de formar el primer grupo de rock en Argentina en hacer blues en castellano, Gabis participó de uno de los más extendidos encuentros de difusión de la nueva música y estética juvenil: el happening Be at Beat Beatles. Realizado en octubre de 1967 y organizado por el artista y sociólogo Roberto Jacoby en conjunto con Miguel Ángel Telechea y Daniel Armesto en el IDT. Se trataba del "Primer homenaje mundial a los hippies" a través de un "espectáculo envolvente y multisensorial" con "el sonido más sensacional de todos los hippies y la gente más linda de Buenos Aires".

Marta Minujín fue otra referente del Di Tella que contribuyó a la difusión de lo hippie en Buenos Aires. Esta artista vivió en Nueva York entre 1967 y 1969, aunque ya había estado allí previamente para presentar sus happenings en distintas galerías y para investigar sobre escultura creativa gracias a una beca Guggenheim que había ganado para el período 1966-1967 (Villa 277). Esta vez, la joven y consagrada artista se había trasladado a Nueva York para exhibir su obra Minuphone, desarrollada en diálogo con la teoría de los medios de Marshall McLuhan, con quien había estudiado en Canadá. Tras conocer la escena hippie, invitada a través de un amigo -el dramaturgo chileno Claudio Badal, conocido luego por haber sido uno de los organizadores del Be-in en el Central Park en 1967-, abandonó las galerías de arte y comenzó a vivir como una hippie: durmió en el Central Park, consumió cotidianamente ácido lisérgico, comenzó una dieta macrobiótica y se mantuvo con escasos ingresos (García, F. 57).

3 "Be at Beat Beatles", Gacetilla de Prensa. Archivo Di Tella, Centro de Experimentación Audiovidual (CEA), Caja 10. Universidad Torcuato Di Tella. 
FIGURA 1

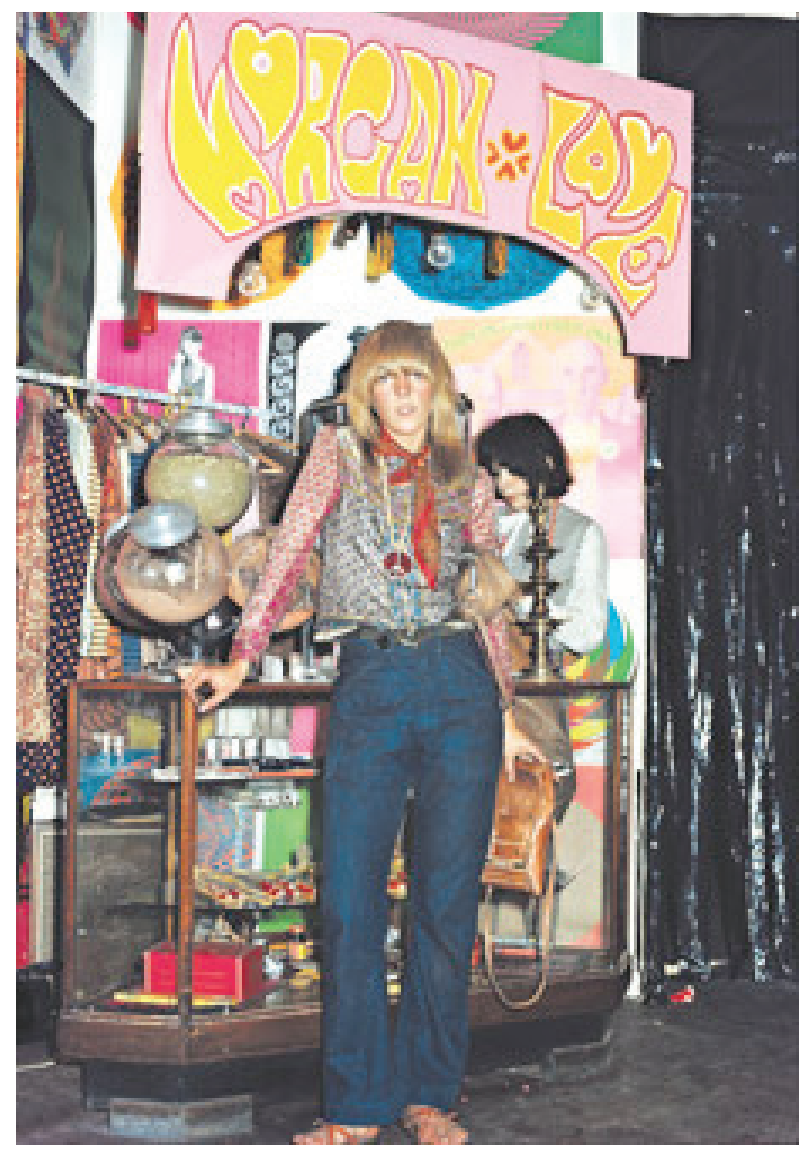

Marta Minujín ataviada al estilo hippie durante la presentación de su obra "Exportación/Importación". Instituto Di Tella, Archivo Marta Minujín, Buenos Aires, 1968.

A su regreso en Buenos Aires, lo "underground" ingresó a las salas de arte. Entre el 22 y el 31 de julio de 1968 Minujín presentó en el Instituto Di Tella una obra llamada Importación-Exportación. Se trataba de un proyecto que se esperaba realizar en dos tandas, una en Buenos Aires y otra en Nueva York. El objetivo era importar a Buenos Aires la visión de Minujín sobre la cultura hippie para luego exportar elementos de la cultura joven porteña a Estados Unidos ("Lo más en la onda" 23). Sin embargo, solo se realizó la fase de la importación y, para "comprar" la cultura hippie, Minujín contó con un presupuesto otorgado por el Instituto que le permitió adquirir los más destacados productos del Greenwich Village y del Haight-Ashbury, el otro extendido barrio hippie norteamericano ubicado en la ciudad de San Francisco. Traídos en un contenedor, fueron exhibidos posters, periódicos underground, indumentaria, bijouterie, objetos decorativos, discos y luces estroboscópicas (Fig. 1) ("El flower power" 59). Esta exhibición permitió expandir las fronteras de circulación de la contracultura a un público más extendido del logrado por Grinberg y Gabis. Según el diario La Razón, 
la obra Importación-Exportación fue visitada por unas mil personas, especialmente adolescentes de ambos sexos ("La rural" 90).

Minujín continuó en otras actividades creativas su apreciada pertenencia al mundo de los hippies, y esto derivó en diferentes obras colaborativas con algunos de los primeros "náufragos". Su periódico Lo Inadvertido (1969), escrito y dibujado a mano alzada, inspirado en la tipografía, los dibujos y los colores psicodélicos, contó con colaboraciones de músicos como Alberto “Tanguito" Iglesias, Javier Martínez, Luis Alberto Spinetta y Miguel “Abuelo” Peralta. Además, el constante interés de Minujín por musicalizar sus happenings y por ambientar psicodélicamente a sus obras, contribuyó a consolidar la presencia de los grupos de rock, en especial de Almendra y Manal, en las salas del Instituto Di Tella, quienes a partir de 1969 comenzaron a ofrecer recurrentes presentaciones en vivo durante el ciclo "Espectáculos Beat".

Por último, otro de los viajes que ampliaron las referencias de una cultura rock acotada a la escasa y filtrada información que llegaba a Buenos Aires en los sesenta fue el realizado por Jorge Álvarez, reconocido editor de libros, y Pedro Pujó, otro joven egresado del prestigioso Colegio Nacional Buenos Aires y futuro productor del primer sello local de música rock "Mandioca. La madre de los chicos”. Álvarez y Pujó viajaron a Nueva York en 1968 con el objetivo de negociar los derechos de autor para la versión norteamericana del libro Mi amigo el Che de Ricardo Rojo (Álvarez 63). Después de vivir un mes en el Greenwich Village, volvieron con el proyecto de instalar en una manzana del histórico barrio porteño de San Telmo un lugar que replicara el estilo de la bohemia neoyorkina, con salas de cine, departamentos, restaurantes, tiendas de moda y lugares destinados a la realización de conciertos de rock. Aunque la Sociedad de Amigos del Barrio de San Telmo impidió que se realizara el proyecto por temor a que la fisonomía del barrio cambiase, la iniciativa se prolongó a una serie de actividades que incluyeron desde la realización de diversas performances callejeras inspiradas en el Living Theatre y Allan Kaprov, la producción local de pósters, la creación del sello discográfico ya mencionado y la organización de ciclos de recitales de rock en teatros del centro y clubes del Gran Buenos Aires (Pujó).

Estas iniciativas contribuyeron a atraer el interés sobre el fenómeno hippie entre los jóvenes logrando que las reducidas fronteras con las que originalmente había sido recibido comenzaran a expandirse. En dicho marco, editoriales y discográficas cobraron interés por lo hippie y comenzaron a publicar manuales introductorios a sus principios ideológicos, como también discos cuyas compilaciones contribuían a la conformación de un gusto musical psicodélico. El argentino Juan Carlos Kreimer, quien inició su trayectoria de escritor y periodista en la revista Eco Contemporáneo y viajaba con frecuencia a Estados Unidos para escribir reseñas sobre la escena rock

4 Además de los ya mencionados, otros grupos de rock que también se presentaron en el escenario del CEA del IDT entre 1969 y 1970 fueron Arco Iris, Miguel Abuelo, Carlos Cutaia, Pappo, Héctor "Pomo" Lorenzo, los platenses La Cofradía de la Flor Solar y Diplodocum Red \& Brown y, los ahora olvidados, Fernando Mosquera Nono, Cosa Nostra y Harlem R. \& B, ; “Noticas para la prensa”, Archivo Instituto Di Tella. 
en la masiva revista femenina Claudia, publicó en 1968 el libro Beatles \& Co, una de las primeras historias locales del rock internacional (Rial Ungaro).

$\mathrm{Al}$ año siguiente, la editorial Brújula, publicó en castellano El libro hippie del periodista y crítico musical norteamericano Jerry Hopkins, que reunía ensayos sobre el amor libre, el antimilitarismo, el consumo de drogas alucinógenas, cartas de lectores editadas en distintas revistas de la llamada prensa subterránea. Ese mismo año, la editorial Emecé inició la distribución en Buenos Aires de la traducción española de Los hippies. Quiero ver a dios de frente del francés Michel Lancelot donde se explicaban los orígenes religiosos y políticos del hippismo. Por otra parte, la subsidiaria local de свs editó entre 1968 y 1969 varias compilaciones con las novedades de la música hippie: Flower Power. Música para hippies (1968), Más música para hippies "Flower Power" (1968), Hippiedelico '69 (1969) y Música Hippiedelica volumen 2 (1969). Estos libros y discos fueron promocionados con recurrencia en revistas de información general y de gran tirada, así como también en las nuevas revistas juveniles que se multiplicaban al tiempo que los "conjuntos beat" locales alcanzaban cada vez más popularidad. ${ }^{5}$

En efecto, el inicio de la década del setenta ofreció un nuevo panorama para los interesados por el rock contracultural en Buenos Aires. Las primeras caminatas musicalizadas se habían convertido en convocantes recitales que atraían a un nutrido grupo de jóvenes, en gran medida estudiantes de colegio secundario de diversa extracción social, a los encuentros en teatros y clubes deportivos de barrio. Con todo, las posibilidades de poner en práctica los bucólicos rituales de los hippies norteamericanos en los recitales resultaron más difíciles de concretar en Buenos Aires. Si bien los jóvenes de otras ciudades latinoamericanas tuvieron su propio Woodstock, como fue el caso de "Piedra Roja" (octubre de 1970) en Los Domínicos, a pocos kilómetros de Santiago de Chile y el "Festival de Avándaro" (septiembre de 1971) en las cercanías del Distrito Federal de México, el intento por realizar un festival de estas carnavalescas características en la localidad de Lobos, a unos 100 kilómetros de Buenos Aires, fue prohibido después de un seguimiento de inteligencia policial. En el marco de un conservador gobierno militar, el encuentro fue asociado con "acontecimientos extranjeros" que fomentan el consumo de drogas y proponen "desviaciones al terreno inmoral con presuntas implicancias políticas ajenas a nuestro modo de vida" (Policía de la Provincia de Buenos Aires). Este fallido intento fue reemplazado por el "Festival B.A.Rock". Si bien su organizador lo asociaba con Woodstock, el recital -auspiciado por el gobierno municipal- se realizó en un espacio más controlado. El público escuchó durante cinco tardes a los músicos, sentado en las gradas de un estadio deportivo al interior de un parque urbano (Sánchez Trolliet, "Del sótano al estadio" 183).

5 A partir de 1967 se multiplicaron las revistas juveniles comerciales de temática rockera e inspiradas en el pop y la piscodelia. Con dispares resultados en el mercado editorial se cuentan: JV (1967), Pinap (1968-1970), Alquitrán (1970), La Bella Gente (1970-1973); Cronopios (1970), Pelo (1970-1995), Ritmo Beat (1970) y Ruido Joven (1970). 
En cuanto a la calidad musical, los artistas y los críticos evaluaban a la escena local en función del grado de similitud respecto de los "grupos extranjeros". En la revista Análisis, por citar un ejemplo, el crítico Jorge Andrés, celebraba al cuarteto Almendra por ser "el único exponente local capaz de cotejar con la competencia extranjera" (Andrés, "Los jóvenes fuertes" 48). Este tipo de comparaciones alentó a algunos músicos (Edelmiro Molinari y Emilio del Güercio de Almendra, de Ciro Fogliatta de Los Gatos y Alejandro Medina y Claudio Gabis por Manal) a viajar en 1970 a Estados Unidos para conocer las escenas de concierto y hacerse de instrumentos y equipos de amplificación más sofisticados con el fin de mejorar el sonido de los recitales que solían tener desperfectos técnicos.

Dichos viajes contribuyeron a desmitificar la imagen que los jóvenes contraculturales locales tenían de Estados Unidos en, al menos, dos sentidos diferentes. Por un lado, porque estas crónicas mostraban un país que no parecía ser tan libre como la imagen que habían recibido de los hippies y, por otro, porque sirvieron para afirmar la calidad de la música local al constatar que la norteamericana no parecía ser tanto mejor de la que en Buenos Aires se podía escuchar. Ciro Fogliatta, de Los Gatos, afirmaba:

Esto que cuento es solo Nueva York, y dentro de esta ciudad el Village, el resto es diferente. Yo, por ejemplo, estuve en el sur, Jacksonville, Charleston, Baltimore, también en Philadelphia. En esas ciudades todo es distinto, no hay movimiento. Es más: uno cree que en Estados Unidos todo es muy libre, muy lindo y que podés hacer lo que se te antoje, pero no es así: en estas ciudades que te digo del sur, los conductores de ómnibus me decían las mismas cosas que te dicen en la calle en Buenos Aires por usar el pelo largo (“¿Qué viste en UsA Ciro?” 40).

Así, al descubrir que "la música argentina no está muy lejos de la de U.s.A", los artistas locales reforzaron la confianza en la posibilidad de consolidar una escena rock local duradera, que encontrara su voz local sin perder las pretensiones de calidad y originalidad que llegaban desde el norte.

\section{Inglés vs. español}

Los pioneros del rock contracultural local imaginaron un destino porteño para este género musical en ciernes. Para ellos su música ofrecía las temáticas y cadencias melódicas más adecuadas para interpretar la experiencia urbana contemporánea de los jóvenes. Esta propuesta surgía al mismo tiempo que en el panorama musical de la ciudad se advertía un vacío. El tango, que durante medio siglo había hegemonizado la representación musical de Buenos Aires, estaba perdiendo su capacidad de vehiculizar sonidos e imágenes actualizadas sobre la vida urbana contemporánea. Enrique Cadícamo, letrista de memorables canciones de tango de los años treinta, exhortaba a no "hablar más del arrabal, de la mina [mujer] que se escapó de la casa" porque "eso era 
en el Buenos Aires de hace veinte años" (Urondo 96). Por otra parte, Astor Piazzola quien había estado liderando la principal renovación del tango al fusionarlo con el jazz reconocía que "la música hoy, exige una cosa distinta" y que:

Buenos Aires tiene necesidad de poetas contemporáneos, que sientan la ciudad de Buenos Aires-hoy. Gente como Cadícamo, Cátulo Castillo, Contursi -siendo buenos letristas- me da la impresión que pertenecen a otra época, que no pertenecen al Buenos Aires-hoy [...]. Ellos también tocan y sienten como hace treinta años ("Diálogo con Piazzola" 158).

Pese a los esfuerzos de modernización impulsados en el tango, el género transitaba su ocaso y, por ello, desde diversas revistas culturales, se anunciaba la necesidad de que una nueva música popular narrara la vida urbana contemporánea (Schoo 38). En este marco, músicos y poetas identificados con el rock se sintieron los legítimos herederos del tango para dar con una nueva voz que pudiera pintar con melodías a la moderna Buenos Aires. El rock, un "ímpetu sonoro que abrió una brecha en las ciudades del tango", emergía como un género musical acorde a su tiempo y a los sentimientos de los "ansiosos jóvenes de la gran ciudad moderna [...] invadidos por el concreto, la TV y los transistorizados instrumentos de una era dominada por las comunicaciones masivas" ("Beat Buenos Aires" 52). En el retrato musical de la Buenos Aires contemporánea, la llamada música beat ofreció una versión que pretendía ser auténtica, moderna, contestataria y, específicamente, juvenil. También ofrecieron sus versiones el folklore y la Nueva Canción argentina. Sin embargo, el folklore respondía a la necesidad de insertar en la vida urbana las realidades del interior rural y, la Nueva Canción (con artistas como Nacha Guevara, Dina Rot o Jorge de la Vega) nunca logró interpelar de modo contundente al público joven (Pujol).

Así pues, al igual que el tango antes, la sociabilidad de los hippies-rockeros dio forma a un léxico original que se proponía inaugurar una auténtica forma de expresión de la cultura urbana de Buenos Aires (Caimari 157). El "lunfardo rockero", surgido durante las caminatas de los náufragos, comenzó a ser incorporado en la escritura corriente de muchas revistas juveniles, y también a ser sistematizado en diversos diccionarios publicados en otras revistas de información general, incluso en la revista oficial de la policía federal. Este glosario estaba compuesto por palabras inventadas y por otras ya existentes, pero con nuevo significado. Con "pizza", el giro local de "zapada" -la improvisación musical- o "sanata", que aludía a los malos músicos, el argot rockero creaba una jerga específicamente musical. Además, los nuevos fonemas aludían al modo en que experimentaban la vida en la ciudad a través de sus prácticas cotidianas: "estar en el humo" o "fusilado", hablaban del consumo de la marihuana y de sus efectos; "me borro" y "secuestrar" aludía a quien dejaba de frecuentar los ámbitos de encuentro. En tanto, "reventado" y "mufado" insistían en la ideología contestataria de sus adscriptos y "senever" se refería al tiempo -en general excesivo- existente entre que se despertaban y se volvían a dormir. Además, este último término aludía a la 
búsqueda de nuevas medidas del tiempo por fuera de las rutinas del mercado laboral y de los estudios universitarios que rechazaban como opción legítima de ingreso a la vida adulta. Otras palabras como "beca" o "salir de garante" manifestaban la negativa a participar de las rutinas propias de una sociedad integrada al mundo del trabajo (Torre 247-59), para ejercer otras estrategias económicas que les permitieran solventarse sin ser empleados (“Diccionario" 29, "El cantar de la juglaría” 255, De Zer 42-5).

Otra expresión infaltable era "hombres azules”, que refería a los agentes policiales, un actor social siempre presente en la cotidianeidad de los rockeros. En el marco de la campaña de "moralización pública de la ciudad", que había sido implementada al iniciarse el gobierno de la autoproclamada "Revolución Argentina", los jóvenes rockeros, especialmente los varones, fueron hostigados, detenidos en la comisaria y catalogados indistintamente - hasta fines de la década - como "vagos" o "comunistas" (Avellaneda 97). Tal como se desprende de Mundo Policial, la revista cultural de la policía de la ciudad, esta institución todavía identificaba a la cultura de Buenos Aires con el tango pues lo consideraba patrimonio policial. Se reivindicaba el linaje uniformado de varios tangueros célebres -como Enrique Santos Discépolo o Edmundo Rivero ("Discépolo tango y policía" 22, "Edmundo Rivero" 57)-, mientras que el hipismo era considerado como un sistema organizado de delincuencia internacional. En esta revista tampoco faltaron referencias al glosario hippie: se reprodujo un diccionario en inglés con los términos más repetidos por los norteamericanos (drop out, turn on o tune in), y también se aludía a las formas del habla de los náufragos locales, sobre todo a aquellas palabras que traslucían el rechazo al trabajo y sus preferencias por las drogas ("Hippies. Eslabones policiales" 8-11).

Estas inflexiones idiomáticas que filtraban las aspiraciones de los jóvenes rockeros como también las condiciones de su integración a la sociedad, fueron una parte del proceso de criollización del rock que, a diferencia de lo que ocurrió en otros países de la región, se dio de modo irrevocable a través del lenguaje. En el plano musical, los artistas no optaron por "latinoamericanizar" su sonido. El cosmopolitismo musical primaba como criterio para la experimentación creativa y, por ello, en la composición musical se omitían las preocupaciones por las fronteras nacionales. Si bien existieron algunas excepciones, esto no alcanzó para que los primeros tiempos de la producción local del rock estuviera caracterizados por una distintiva sonoridad con color local. ${ }^{6}$

Los diálogos culturales y musicales de los rockeros locales se estrechaban con referencias ajenas al legado amerindio. Poco espacio hubo para las quenas, los sikuris o los charangos que, por ejemplo, sonaban intensamente entre los chilenos Jaivas y Congreso o los colombianos Génesis (Cepeda Sánchez) o para la fusión del rock

6 Entre las excepciones se cuenta a Arco Iris, uno de los grupos que más impulsó los giros latinoamericanistas y grabó en su primer disco un tema con ritmo de zamba; o las orquestaciones con aires lejanamente tangueros que grupos como Almendra o Pedro y Pablo incluyeron en algunas de sus canciones: "Laura va" (Almendra, Almendra. RCA, 1969. LP) y "Yo vivo en una ciudad" (Pedro y Pablo, Yo vivo en esta ciudad. CBS, 1970. LP). 
anglosajón con los tradicionales ritmos locales como sucedió en Uruguay con el candombe o en Brasil con el samba. Los músicos porteños que en el plano musical no pretendían distanciarse demasiado de los sonidos oriundos de las metrópolis anglosajonas buscaron marcar el ritmo de la diferencia en el plano del lenguaje. Además, la falta de familiaridad con el inglés y la extrema distancia geográfica de Buenos Aires con los centros hegemónicos de producción de rock volvía improbable que en el corto plazo se contaran con posibilidades concretas de encontrar un público angloparlante, como sucedía, por ejemplo, en México. ${ }^{7}$ De allí que el español se haya convertido rápidamente en el idioma principal del rock local. ${ }^{8}$ Los rosarinos The Wild Cats al llegar a Buenos Aires en 1965 cambiaron su nombre por Los Gatos; los primeros simples de Los Beatniks editados en 1966 eran canciones propias cantadas en castellano, los músicos de Bubbling Awe y The Seasons cuando se fusionaron en Manal hacia 1967 abogaron por convertir al español en el nuevo idioma del blues. El uso del español en las canciones no solo legitimaba a los músicos pues partía aguas entre los "buenos" y "malos" compositores. Además, impugnaba la supremacía del inglés en la expansión mundial del rock, pues ponía en cuestión la creencia por aquel entonces compartida de que el ritmo del rock se llevaba mal con la métrica y la entonación del español (Ripoll 1).

Con todo, no existía un extendido consenso sobre esta cuestión y hacia 1970 algunos grupos todavía seguían cantando en inglés. El Trío Galleta era uno de ellos y en el tercer número de la ya consagrada revista Pelo sus músicos hicieron una serie de declaraciones polémicas que despertó la rancura de los lectores del mensuario. Los miembros del grupo declararon a la revista su negativa a cantar en castellano y a componer temas propios. Preferían cantar en inglés y hacer covers de Creedence o The Doors porque -alegaban- en Argentina "estamos atrasados diez años" ("El trío vale”). En los números siguientes de Pelo, el correo de lectores se encendió con manifestaciones nacionalistas sobre el rock local. Si bien se reconocía cierto retraso respecto de la música extranjera, se le reprochaba al trío no invertir su esfuerzo y talento en el "desarrollo de la música Argentina" y mantenerse "dependientes" a referencias extranjeras (Santoro, "Correo de lectores" 54). Los lectores de la revista

7 Como ha explicado Eric Zolov, la cercanía cultural y geográfica de México con Estados Unidos mantuvo la hegemonía del inglés no solo porque existía la posibilidad de hacer presentaciones en vivo frente a un público angloparlante sino también porque el uso del inglés se configuró como una forma de trasgresión al nacionalismo mexicano.

8 Este proceso de traducción se había iniciado con los músicos "comerciales" de la nueva ola a fines de los años cincuenta. Pese a su estilo edulcorado y escasamente crítico de las convenciones sociales, los músicos "nuevaoleros" impulsaron la combinación de estilos norteamericanos con el canto en español. En los años siguientes, al propagarse las escenas de rock contracultural por la región, el uso del español se mantuvo en el canto: fueron traducidas canciones anglosajonas e incluso los músicos componían temas originales en castellano. En Chile, Los Mac's hacia 1966 ya combinaban en sus discos canciones en inglés, con covers y temas propios cantados en español y en 1969 los High \& Bass trocaron su nombre por Los Jaivas. El uso del español también se verifica de modo temprano en Uruguay con El Kinto e incluso esta misma operación se verifica en Brasil con el portugués, donde la lengua lusitana fue incorporada en el primer disco de Os Mutantes y en las tempranas composiciones de los músicos tropicalistas. Sin embargo, en Buenos Aires, el uso del idioma local tendió a ser visto por los músicos y periodistas de rock como una marca de distinción y originalidad (Kreimer, Ayer nomás). 
destacaban, en contraposición, la labor de Almendra, Los Gatos y Manal que eran grupos "evidentemente nacionales" que "con su esfuerzo y talento" daban a "nuestra música pop la evolución necesaria”.

Al hablar de un rock "nacional" y en "desarrollo" que no debía ser "dependiente" de lo "extranjero", músicos, periodistas y público de rock se apropiaron de categorías interpretativas de gran circulación en su época para comprender su propia práctica (Santoro, "Se ponen en genios" 44). En el contexto de creciente politización y radicalización de amplios sectores juveniles, la cuestión de lo nacional en el rock comenzó a ser un tema recurrente entre los jóvenes contraculturales. Se trataba de una total novedad impuesta por la coyuntura que venía a superponer las expectativas por hacer del rock una música urbana con las nuevas demandas por la autenticidad nacional.

\section{"Se enseña a pensar en inglés"}

Hacia el final de "Neocolonialismo y Violencia", la primera parte de la trilogía del film político-documental La hora de los hornos (1968), puede escucharse la canción "I don't need no doctor" de Ray Charles y una cita de algunos segundos de "Sgt. Pepper's Lonely Heart Club Band" de The Beatles, mientras se suceden escenas de la cultura juvenil en el microcentro de Buenos Aires: en una disquería, chicos y chicas revisan las bateas y mueven su cuerpo al compás de la música y luego, el Instituto Di Tella, su sala de exhibiciones y un grupo tumultuoso de hippies que bailan, comen bananas y pregonan ser "universales y cósmicos". Las citas a Ray Charles y The Beatles contrastan radicalmente con las percusiones y los cantos con aires africanos y latinoamericanos que predominan durante buena parte del film y que acompañan escenas de pobreza e injusticia en diferentes paisajes del interior del país.

La elección de la música no es azarosa y se corresponde con el programa interpretativo más general de la cultura argentina que el film delineaba. La hora de los hornos se fundaba en una interpretación maniquea de la cultura que contraponía lo nacional y auténtico con lo extranjero y espurio. Realizada desde 1966 por los integrantes del Grupo Cine Liberación, La hora de los hornos se postulaba como un ejercicio de concientización y activación política de la juventud. Se trataba de una película militante orientada a la lucha de liberación nacional en el marco de una retórica que identificaba a Argentina con los pueblos del Tercer Mundo (Albornoz y Ribadero; España; Mestman). El mensaje que recibían sus espectadores consistía en una denuncia a la invasión y la violencia que el imperialismo económico y cultural de los países centrales, en especial Estados Unidos, provocaba en una vida nacional que necesitaba combatir por su liberación. Argentina no solo tenía que lidiar con el imperialismo en el plano externo sino también en el interno. Por esto se convocaba a una "descolonización del gusto" y se acusaba a la "oligarquía" y a la "pequeña 
burguesía" de calcar los gustos y modas de las metrópolis centrales fomentando un "complejo por lo nativo" que "enseña a pensar en inglés" y reniega de las tradiciones locales (Aguilar 92).

No resulta extraño entonces que el Rhythm and Blues de Ray Charles y el rock de The Beatles aparecieran en el film en tanto ejemplos paradigmáticos de la "colonización mental" de unos sectores medios urbanos que habían sucumbido ante los efectos de una manipulación que, según podía escucharse en el film, intentaba "despolitizar al pueblo" y "sembrar el escepticismo". Poco importaba que Ray Charles fuera un activo luchador por los derechos civiles o que los Beatles hubieran revolucionado el modo de hacer música en el mundo: cuando oían estas melodías y su canto en inglés, los realizadores escuchaban el idioma del sometimiento y una forma disolvente de la cultura nacional.

La visión del Grupo Cine Liberación no era una excepción en el contexto local de fines de los años sesenta. La película procesaba en clave audiovisual elementos que estaban presentes en el discurso de una gran cantidad de jóvenes universitarios de clase media que, hacia el fin de la década, irrumpieron en la escena pública y se vincularon con vehemencia a una política militante de izquierda, ya fuera en su versión peronista o marxista, para combatir, como ha apuntado Juan Carlos Torre, "un orden que aparecía a sus ojos como moralmente injusto y políticamente cínico y corrupto" (249).

Una serie de tópicos se convirtieron en un nuevo sentido común compartido por estos jóvenes. Para ellos, el fin de la década estuvo signado por una necesidad inminente de cambio que se vio reforzada por el éxito de la revolución cubana, la revuelta obrero-estudiantil de la ciudad de Córdoba, la confianza en el advenimiento de una nación socialista, el descrédito por las formas de organización política democráticas y la sobrevaloración de la violencia como mecanismo de transformación social (Sorensen, Tortti). Asimismo, emprendieron un "movimiento hacia el pueblo" que supuso identificarse con los sectores obreros y consolidar una retórica nacionalista y latinoamericana que valorizaba positivamente las culturas de las provincias argentinas históricamente marginadas (Altamirano; Manzano, "Making third world Argentina"). Este alineamiento geopolítico hacía cuestionar a los "copetudos [engreídos] yanquis" tanto por su política exterior, tras las incursiones militares de Vietnam, República Dominicana y Cuba, como también por su modelo cultural. ${ }^{9}$ La fuerte pregnancia de valores románticos y anticapitalistas entre los jóvenes radicalizados los hacía despreciar el estilo de vida del consumo de masas norteamericano.

9 La expresión "yanquis copetudos" pertenece a la novela Para hacer el amor en los parques de Nicolás Casullo (sociólogo y militante montonero que en los años del gobierno de Cámpora estuvo al frente del área de comunicación educativa dependiente del Ministerio de Educación donde se realizaron distintos proyectos culturales en sintonía con la retorica de la liberación nacional). 
Los jóvenes que se identificaban con las organizaciones de izquierda sintonizaron sus gustos culturales de acuerdo con este giro. Respecto de sus preferencias musicales, se identificaron con las sonoridades de la Nueva Canción Latinoamericana y, en especial, la proyección folklórica, ya que sus temáticas y su origen vernáculo les permitían canalizar sus expectativas de cambio en torno a una conciencia nacional, latinoamericana e identificada con las luchas de los trabajadores rurales (Molinero). ${ }^{10}$

Si bien la utilización política de la música de raíz nativa no era una novedad, la transformación de sentido que tuvo el consumo del folklore en Buenos Aires sí resultó original. Desde los tiempos del Centenario, el folklore había sido introducido como parte del repertorio nacional tradicional. También en la música docta, Alberto Ginastera, había incorporado desde los años treinta citas folklóricas como parte de su proyecto de nacionalización musical (Sottile 150). En los años peronistas, el legado musical provinciano fue recuperado positivamente. Con el fin de "metropolizar la cultura popular" (Chamosa 146), las políticas culturales del peronismo incorporaron al folklore en los programas de música de los colegios nacionales y normales, y crearon diversos organismos e instituciones que le dieron cobertura política y financiera.

Por ello, aunque la música de raíz folklórica era parte de lo que se consideraba como un acervo nacional indiscutible, fue recién hacia la segunda mitad de los años sesenta cuando toda una industria cultural vinculada a la música nativa se levantó en una ciudad que se había "folklorizado". ${ }^{11}$ De modo que no fueron los jóvenes militantes los primeros en emprender esta recuperación positiva del folklore. Esta apropiación puede interpretarse como el resultado de un largo proceso de aceptación de la presencia provinciana en la ciudad por parte de los sectores medios. Como ha señalado el folklorista y antropólogo Ariel Gravano, este boom vino a concluir con los tiempos del rechazo al "cabecita negra" y a la cultura popular provinciana instalada en la ciudad (Gravano, "La música de proyección”).

El historiador y folklorista Félix Luna anunciaba desde su revista Folklore en 1965, que este género había dejado de ser interpretado como "cosa de negros" y se había convertido en una manía "un poco snob" entre las clases medias de origen europeo ("Argentina Capital Buenos Aires" 7). Músicos como Ariel Ramírez, Los Fronterizos o Los Chalchaleros ofrecían una imagen moderna de la música nativa que se difundía en un nuevo paisaje del entretenimiento urbano crecientemente folklorizado (Chamosa).

$\mathrm{Al}$ igual que lo sucedido con muchas otras producciones culturales en las artes visuales o el teatro (Longoni, Verzero), el folklore inició un proceso de politización. En 1964, la tucumana Mercedes Sosa y los mendocinos Armando Tejada Gómez,

10 Los términos "canción nativa", "folklore" y "proyección folklórica" son utilizados aquí como sinónimos. Pero resulta necesario aclarar que, como ha destacado Ariel Gravano, "folklore" alude a los fenómenos producidos espontánea o tradicionalmente en una región determinada mientras que la "proyección folklórica" remite a las obras artísticas destinadas a un público urbano que recrean el estilo de la cultura popular (El silencio 17-22).

11 Además, por fuera de la geografía porteña, el Festival de Cosquín realizado en la provincia de Córdoba a partir de 1961 contribuyó a aumentar la visibilidad en todo el país de los géneros musicales folklóricos (Marbiz 6-45). 
Oscar Matus y Tito Francia, entre otros músicos vinculados al Partido Comunista, se desplazaron hacia Buenos Aires para difundir un nuevo programa musical que, como planteaba Mercedes Sosa, se proponía renovar el "folklore barato y adormecido" a partir de originales composiciones "con fundamento" y contenido militante (García, M. 79). Este proceso de politización del folklore que se intensificó hacia el final de la década, retroalimentó a la militancia juvenil y consolidó un criterio del gusto musical que giró en torno a las nuevas generaciones de compositores y letristas folklóricos “comprometidos" como César Isella, Jorge Cafrune, Víctor Heredia, José Larralde, Chango Farías Gómez, y a los artistas de la Nueva Canción Latinoamericana, como los chilenos Ángel y Violeta Parra, Víctor Jara y Quilapayún, el uruguayo Daniel Viglietti y los cubanos Silvio Rodríguez y Pablo Milanés.

Esta extendida sensibilidad musical telúrica tendió a condicionar negativamente los oídos de los jóvenes politizados hacia los electrificados sonidos del rock. Las primeras tomas de posición críticas entre los sectores de izquierda surgieron en publicaciones del tradicional Partido Comunista como Juventud y Cuadernos de Cultura. Las impugnaciones estuvieron dirigidas a las versiones locales de los "ídolos mediáticos" y los músicos de la "nueva ola" que proponían imitaciones locales de Elvis Presley y los Beatles. Estos "sonidos sorprendentes y agradables" -alegaban- son los responsables de "hacernos perder nuestras características propias de argentinos" dado que los "norteamericanos coherentes con su política de dominio, tratan de mantener la american way of life en Latinoamérica [...] y tratan de dominar la vida musical de nuestro pueblo” (“¿Qué bailan en carnaval?” 8).

Incluso, a medida que los músicos de rock locales fueron diversificando su producción artística y complejizando sus referencias culturales a partir de la multiplicación de revistas, libros, panfletos o manifiestos autodefinidos como contraculturales, los intelectuales de izquierda mantuvieron un diagnóstico negativo sobre el fenómeno rockero. En 1971, el escritor Germán García publicaba en la revista Los Libros una dura reseña de Agarrate!, la primera historia del rock local escrita por el periodista argentino Juan Carlos Kreimer. La molestia de García radicaba en la celebración que allí se hacía del rock como un arte "subversivo" pues para él esta descripción no era más que una "convulsión lingüística" que ocultaba un artilugio "impuesto por la política norteamericana” (García, A. 36-7).

Una insalvable dicotomía parecía separar a rockeros y militantes. En efecto, en sus memorias, algunos exmilitantes suelen advertir que su gusto por el rock tendía a ser ocultado o disimulado una vez que ingresaban activamente a la vida política (Manzano, "We don’t want your Revolution" 11). Los rockeros, por su parte, tendían a rechazar las consignas políticas, la lucha armada, las jerarquías partidarias y mostraban un profundo desinterés por ocupar posiciones de poder en el Estado. La ausencia de notas dedicadas a la coyuntura en las revistas más difundidas de la cultura rock evidencia el distanciamiento con estos temas. Sin embargo, la ubicuidad de la política en la vida cotidiana porteña y la creciente visibilidad de la cultura rock en la sociedad tendieron a acercar, no sin conflictos, posiciones y estéticas. 
Aunque en 1974 Luis Alberto Spinetta todavía protestara contra "los tildadores de lo extranjerizante porque reprimen la información necesaria de músicas y actitudes creativas que se dan en otras partes del planeta" (5), lo cierto es que algunas iniciativas aportaron a los promotores de este género musical un nuevo sentido de lo político que ratificó sus pretensiones de rebeldía y permitió reelaborar la conciencia sobre su extranjería. Los músicos de Pedro y Pablo iniciaron un juicio a la discográfica CBs para prescindir del contrato de exclusividad con la compañía norteamericana y su cantante, Miguel Cantilo, junto con algunos miembros de la comuna artística La Cofradía de la Flor Solar, iniciaron un muevo proyecto de vida comunitaria primero en la ciudad, y luego en la Patagonia (Durietz). Por su parte, algunos músicos como Roque Narvaja, "Piero" y Carlos Bisso, representantes de las versiones más comerciales del rock y la canción popular, desarrollaron una nueva actitud musical en la que fusionaron las sonoridades rockeras y el folk con consignas revolucionarias (Fig. 2 y 3). A su vez, Miguel Grinberg, Luis Alberto Spinetta y Emilio del Güercio, organizaron en 1973 una serie de talleres de trabajo multiartísticos que resultaron en una heterogénea conjunción donde participaron jóvenes contraculturales, budistas, siloístas, militantes del peronismo revolucionario, psicólogos experimentales y activistas del Frente de Liberación Homosexual (“Amor y revolución” 30; Grinberg, "La otra cultura" 28).

Pese a la explícita negativa que expresaban muchos rockeros de encuadrar su actitud contestataria dentro de una definición política más ajustada, las simpatías partidarias también comenzaron a filtrarse en los recitales. Así sucedió, por ejemplo, durante el recital de La Pesada del Rock and Roll que, en octubre de 1972, terminó con destrozos en el estadio Luna Park mientras "un sector del pullman trató de inclinar hacia el lado político la reunión y comenzó a cantar Los muchachos peronistas". Aunque los cantos de la tradicional marcha quedaran "inesperada e inexplicablemente, ahogad[os] bajo risas y silbidos", el creciente poder de convocatoria del rock intentó ser aprovechado por los sectores militantes (Andrés, "Desórdenes en el Luna Park" 11). Así, en marzo de 1973, después de que el candidato peronista Héctor Cámpora ganara las elecciones presidenciales después de dieciocho años de proscripción del peronismo, la "Juventud Brigada Peronista" organizó un recital gratuito para celebrar el triunfo electoral en la cancha de fútbol del club Argentino Juniors adonde asistieron unos 20.000 jóvenes. Los músicos fueron convocados por Jorge Álvarez, quien no ocultaba sus simpatías políticas y llegó a asegurar que "la mayoría de los chicos de los conjuntos de rock son peronistas" ("Rock nacional” 50). El festival estuvo plagado de referencias nacionalistas y peronistas: se cantó el himno nacional, se pidió un minuto de silencio por Eva Perón, el vicepresidente electo Vicente Solano Lima dio un discurso y se flamearon banderas con inscripciones de las organizaciones políticas ("La lluvia impidió"). Con todo, la suspensión del festival al poco tiempo de haber iniciado a causa de fuertes lluvias, puede ser vista como una metáfora de las dificultades que tuvieron los rockeros y los militantes de consolidar espacios de encuentro duraderos. 
FIGURA 2

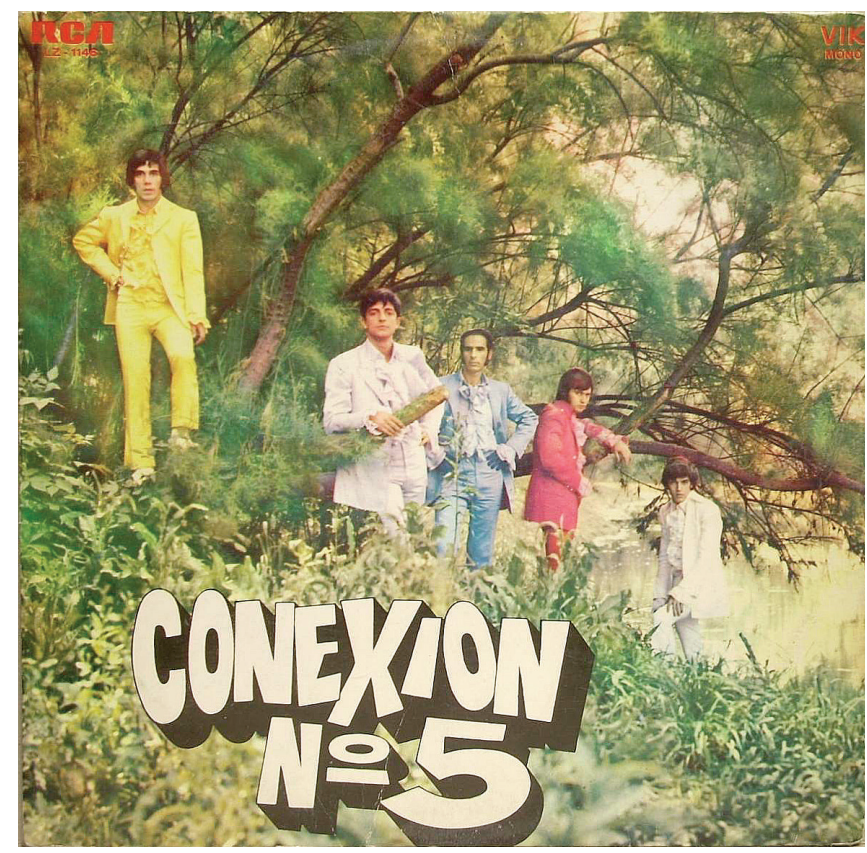

FIGURA 3

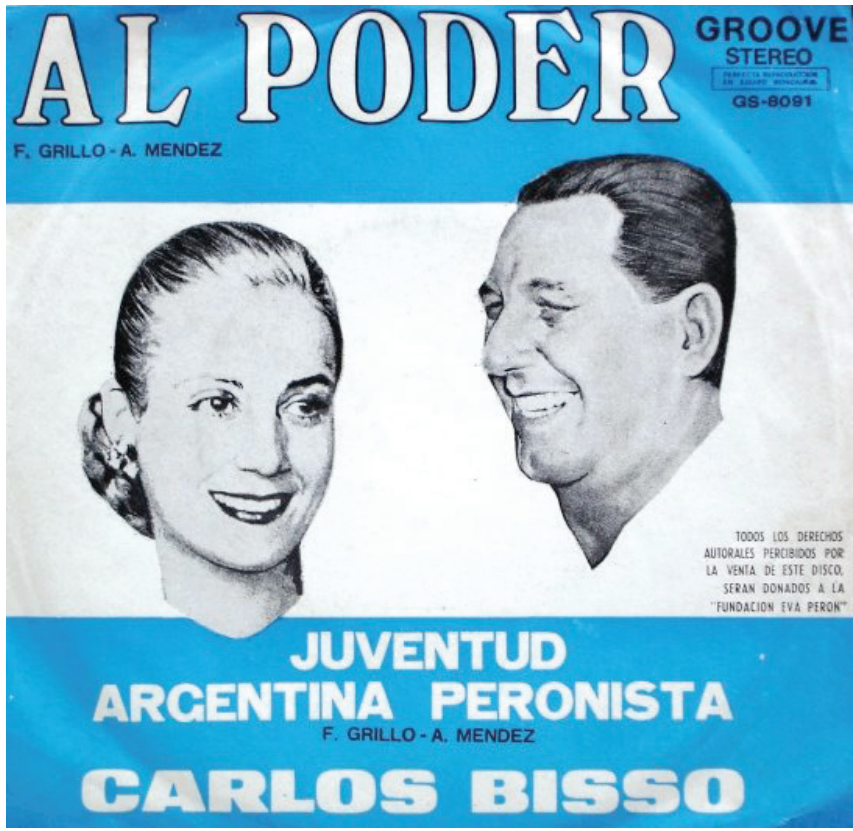

Estética psicodélica de Carlos Bisso. Conexión no 5, RCA-Vik Records, 1969.
En su "versión militante", Carlos Bisso editó un disco simple con las canciones "Al poder" y "Juventud Peronista”. En la tapa del disco puede verse a los retratos de Perón y Evita. Groove-RCA, 1973. 
Esporádicas y difíciles de clasificar dentro de los rígidos marcos de la militancia revolucionaria (Carnovale, Ollier) estas iniciativas contribuyeron a que la cultura del rock iniciara un lento camino de reconocimiento como un fenómeno musical nacional. Como se destacaba en el diario Noticias, dependiente de la organización guerrillera Montoneros, el rock que:

surge, inicialmente, como una imitación de modelos norteamericanos e ingleses[...] se convierte -al desarrollarse- en un medio de expresión de una generación que se manifiesta a través de sus canciones y su música. En ese punto, no tiene sentido considerar al fenómeno como un producto extranjero impuesto, ya que ha superado la etapa de imitación para pasar a la experimentación y creación independiente. En eso, y en su profunda honestidad, reside su empuje. Los adolescentes que apoyan a estos grupos han aprendido perfectamente a diferenciar a los oportunistas de aquellos que realmente tienen algo vital para comunicarles ("Beat argentino"14).

\section{Consideraciones finales}

En este artículo se han aportado algunas claves para comprender el modo en que el rock contracultural "desembarcó" en Argentina en los años sesenta, en especial en Buenos Aires, principal centro de acceso a las novedades de esta cultura musical. El artículo indagó en las expectativas y las ansiedades que despertó entre distintos actores sociales vinculados con la cultura juvenil la llegada de los idearios rebeldes de los hippies, la música rock y la psicodelia. Para ello se trazó un itinerario que puso en conexión las escenas bohemias de las ciudades de Buenos Aires y Nueva York. Como puede advertirse, no se trató de una relación recíproca. Por el contrario, podría afirmarse que el despliegue del mundo contracultural en Buenos Aires estuvo principalmente apuntalado por las novedades que llegaron desde Estados Unidos mientras que los intentos por revertir la dirección de este tránsito no gozaron de la misma suerte.

Aunque conscientes de esta extranjería, los promotores del rock contracultural no tardaron en desplegar un estilo propio que se pretendía auténtico y específico de la idiosincrasia de Buenos Aires. Esta música juvenil y moderna era vista como el relevo generacional del tango que, con un lenguaje renovado, pretendía vehiculizar imágenes vivaces de la cultura urbana contemporánea. Este estilo musical, que se proponía como una forma alternativa de concebir el presente y de imaginar el modo de integración de los jóvenes a la sociedad y la vida adulta en el futuro, no tardó en extenderse, a partir de su integración a las redes de distribución de la cultura de masas, a un público que rebasó la vanguardia cultural que le dio forma en sus primeros pasos.

Mientras que los promotores de este género musical partían de una noción cosmopolita de la cultura y abogaban por conectar a los jóvenes locales con una sensibilidad artística contemporánea e internacional; otros sectores, en especial los jóvenes que 
ingresaban a la política en un contexto de creciente reivindicación de la violencia y de confianza sobre las posibilidades de instalar en Argentina un gobierno socialista, veían en esta misma internacionalidad las causas de la dominación cultural norteamericana. Asimismo, las fuerzas del orden, en especial la policía, adscribieron a esta interpretación del rock como un fenómeno social foráneo y, por tanto, controversial.

De modo que el desarrollo del llamado rock contracultural en Argentina puso en tensión imágenes contrapuestas de Estados Unidos al tiempo que renovó los clásicos debates sobre las posibilidades de imaginar la cultura nacional en relación con lo transnacional. El ingreso de las ideas asociadas con el rock y la nueva izquierda norteamericana ofrecieron una imagen positiva del país del norte en un contexto de creciente impugnación a la política exterior norteamericana entre amplios sectores de la juventud. Por ello, como respuesta al clima ideológico hegemonizado por la política radicalizada, quienes se identificaban con el rock contracultural pretendieron despegar a estas sonoridades de sus tierras de origen para que fueran reconocidas como parte de la cultura local. Esto dio inicio a una concepción del rock renovada donde las referencias a la cultura nacional se superpusieron con las aspiraciones de la cosmopolita identidad urbana de Buenos Aires.

\section{Agradecimientos}

Una versión preliminar de este texto fue discutida en el Taller de Historia ArgentinaEstados Unidos de la Universidad de San Andrés. Agradezco los comentarios recibidos por parte de Laura Cucchi, Ana Romero, Juan Pablo Scarfi, Cecilia Tossounian, Lisa Ubelaker Andrade y su director, Eduardo Zimmermann. También agradezco a Lila Caimari y Alejandro Cattaruzza, por haberme sugerido publicaciones que fueron muy útiles para el desarrollo de este artículo, y a los evaluadores de la revista Aisthesis por sus estimulantes sugerencias.

\section{Referencias}

“Amor y revolución al aire libre”. 2001. Periodismo de Liberación, n 67, 1974, pp. 30.

"Beat argentino contra el oportunismo". Noticias, 22 nov. 1973, p. 14.

“Beat Buenos Aires. Canta la ciudad". Panorama, n 121, 25 agst. 1969, pp. 52-55.

"Diálogo con Piazzolla". Eco Contemporáneo, n 6-7, 1963, p. 158.

“Diccionario". Panorama, $n^{\circ}$ 137, dic. 1969 p. 29.

"Discépolo, tango y policía". Mundo Policial, n 2, 1970, p. 22.

"Edmundo Rivero, un cantor con vocación policial". Mundo Policial, n 4, 1970, p. 57.

"El cantar de la juglaría". Primera Plana, n 255, 14 nov. 1967, p. 68.

"El Flower Power de la calle Florida". Panorama, n 64, 16 jul. 1968, p. 59.

"El trío vale 1.000.000". Pelo 3, abril 1970, s/p.

“Hippies. Eslabones policiales en la cronología”. Mundo Policial, n², 1970, pp. 8-11. 
“Qué bailan en carnaval?”. Juventud. Órgano de la Federación Juvenil Comunista, n 2, 1964 p. 8.

“QQué viste en U.S.A. Ciro?”. Pelo, n² 2, 1970, p. 40.

"La lluvia impidió la concreción de un festival político". Pelo, mzo. 1973, s/p.

"La Rural del Arte en la Calle Florida". La Razón, 23 jul. 1968, p. 90.

"Lo más en la Onda". Clarín, 23 jul. 1968, p. 23.

“Rock nacional: en busca de una definición”. Panorama, n³ 317, 30 my. 1973, p. 50.

Adamovsky, Ezequiel. Historia de la clase media argentina. Apogeo y decadencia de una ilusión. Buenos Aires, Planeta, 2009.

Aguilar, Gonzalo. "La salvación por la violencia: Invasión y La hora de los hornos". Episodios cosmopolitas en la cultura argentina. Ed. Gonzalo Aguilar. Buenos Aires, Santiago Arcos, 2009, pp. 85-120.

Alabarces, Pablo, y Mirta Varela. Revolución mi amor. El rock nacional (1965-1976). Buenos Aires, Biblos, 1988.

Albornoz, Martín y Martín Ribadero. "Representación histórica, violencia y lenguaje en La Hora de los Hornos”. Lucha Armada en Argentina, n¹1, 2011, pp. 164-176.

Altamirano, Carlos. "La pequeño burguesía, una clase en el purgatorio." Peronismo y cultura de izquierda. Ed. Carlos Altamirano.Buenos Aires, Siglo xxi, 2001, pp. 99-128.

Álvarez, Jorge. Memorias. Buenos Aires, Libros del Zorzal, 2013.

Andrés, Jorge. "Desórdenes en el Luna Park frustraron un recital de rock”. La Opinión, 22 oct. 1972, p. 11.

---. “Los jóvenes fuertes”. Análisis, n464, 9 feb. 1970, p. 48.

Avellaneda, Andrés. Censura, autoritarismo y cultura 1960/1983. Buenos Aires, CEAL, 1986.

Barbero, María Inés y Andrés Regalsky, editores. Americanización. Estados Unidos y América Latina en el siglo Xx. Transferencias económicas, tecnológicas y culturales. Buenos Aires, Universidad Nacional de Tres de Febrero, 2003.

Berman, Marshall. "En la selva de los símbolos: Algunas observaciones sobre el modernismo en Nueva York." Todo lo sólido se desvanece en el aire. La experiencia de la modernidad. Buenos Aires, Siglo xxi, 1989, pp. 301-367.

Blanco, Alejandro. Razón y modernidad. Gino Germani y la sociología en la Argentina. Buenos Aires, Siglo xxi, 2006.

Caimari, Lila. "Buenos Aires. Mezclas puras: Lunfardo y cultura urbana". Ciudades sudamericanas como arenas culturales. Ed. Adrián Gorelik y Fernanda Areâs Peixoto. Buenos Aires, Siglo xxi, 2016, pp. 154-73.

Carnovale, Vera. Los combatientes: historia del PRT-ERP. Buenos Aires, Siglo XXI, 2001.

Casullo, Nicolás. Para hacer el amor en los parques. Buenos Aires, Tempo Contemporáneo, 1970.

Cepeda Sánchez, Hernando. "Los jóvenes durante el Frente Nacional. Rock y política en Colombia en la década del sesenta”. Tábula Rasa, n 9, 2008, pp. 313-333. 
Cepeda, Hernando. Imaginarios sociales, política y resistencia. Las culturas juveniles de la música rock en Argentina y Colombia desde 1966 hasta 1986. Bogotá, Universidad del Rosario, 2012.

Chamosa, Óscar. Breve historia del folclore argentino. 1920-1970. Identidad, política, nación. Buenos Aires, Edhasa, 2011.

Cocaro, Gabriel Martín. La Historia del Rock Argentino, 2 ene. 2017, http://www. lahistoriadelrock.com.ar/esp/repo-gabis.html

Cohn, Deborah. "A tale of Two Translation Programs. Politics, the Market and Rockefeller Funding for Latin American Literature in the United States during the 1960s and 1970s". Latin American Research Review, n 41-2, 2006, pp. 139-64.

De Riz, Liliana. La política en suspenso 1966/1976. Buenos Aires, Paidós, 2000.

De Zer, José. “48 horas con los hippies”. Atlántida, n 1209, dic. 1967, pp. 42-45.

Delgado, Julián. Tu tiempo es hoy. Una historia de Almendra. Buenos Aires, Eterna Cadencia, 2017.

Dunn, Christopher. Brutality Garden. Tropicalia and the Emergence of a Brazilian Counterculture. North Caroline, University of North Carolina Press, 2001.

Durietz, Jorge. Entrevista con Ana Sánchez Trolliet, 13 feb. 2013. Inédito.

España, Claudio. Cine Argentino, Modernidad y Vanguardias 1957-1983. Buenos Aires, Fondo Nacional de las Artes, 2005.

Flaschland, Cecilia. Desarma y sangra. Rock, política y nación. Buenos Aires, Casa nova, 2015.

Frank, Thomas. The Conquest of Cool. Business Cultura, Counterculture and theRrise of Hip Consumerism. Chicago, The University of Chicago Press, 1997.

Gabis, Claudio. "Nuevo folklore norteamericano. Poesía y libertad”. Diguem, n 1 , 1966, pp. 3-6.

---. Entrevista con Ana Sánchez Trolliet, 17 oct. 2012. Inédito.

García, Fernando. Marta Minujín. Los años psicodélicos. Buenos Aires, Mansalva, 2015.

García, Germán."Música Beat: Los jóvenes en el espejo". Los Libros, n¹8, 1971, pp. 36-37.

García, María Inés. Tito Francia y la música en Mendoza, de la radio al Nuevo Cancionero. Buenos Aires, Gourmet Musical, 2009.

Garguín, Enrique. "Los argentinos descendemos de los barcos. Articulación racial de la identidad de clase media en Argentina (1920-1960)". Moralidades e identidades de clase media. Estudios históricos y etnográficos. Comps. Sergio Eduardo Visacovsky y Enrique Garguín. Buenos Aires, Antropofagia, 2009, pp. 61-94.

Georgieff, Guillermina. Nación y revolución. Itinerarios de una controversia en Argentina (1960-1970). Buenos Aires, Prometeo, 2008.

Gillet, Charlie. Historia del Rock. El sonido de la ciudad. Desde los orígenes hasta los años 70. Barcelona, Robinbook, 2008.

Gorelik, Adrián. "Buenos Aires. La ciudad y la villa. Vida intelectual y representaciones urbanas en los años 1950 y 1960". Ciudades sudamericanas como arenas 
culturales. Eds.Adrián Gorelik y Fernanda Areâs Peixoto. Buenos Aires, Siglo xxi, 2015, pp.332-337.

Gorelik, Adrián. "Miradas cruzadas. El viaje continental del planning, entre el reformismo y la guerra fría cultural”. Bifurcaciones, 2014, http://www.bifurcaciones. cl/2014/12/gorelik/

Gravano, Ariel. El silencio y la porfía. Buenos Aires, Corregidor, 1985.

---.'La música de proyección folklórica en Argentina”. Folklore Americano, n 35, 1983, pp.5-71.

Grinberg, Miguel. La Generación v. La insurrección cultural de los años 60. Buenos Aires, Emecé, 2004.

---. "La otra cultura". Hurra, n 4, 1980, p. 28.

---. “Pánico en el jardín de las arañas”. La bella gente, n²2, 1971, pp. 70-72.

---. Cómo vino la mano. Orígenes del rock argentino. Buenos Aires, Gourmet musical, 2008.

---. Memoria de los ritos paralelos. Diario de Nueva York. 1964. Buenos Aires, Caja Negra, 2014.

Hopkins, Jerry. El libro hippie. Buenos Aires, Brújula, 1969.

King, John. El Di Tella y el desarrollo cultural argentino en la década del sesenta. Buenos Aires, Asunto Impreso, 2007.

Kreimer, Juan Carlos. Ayer nomás. 40 años de rock en la Argentina 1966-2006. Buenos Aires, Musimundo, 2006.

---. Beatles \& Co. Buenos Aires, Galerna, 1968.

La hora de los hornos. Dirs. Fernando Solanas y Osvaldo Getino, Grupo Cine Liberación / Solanas Productions, 1968.

Lernoud, Pipo. Tanguito y La Cueva. Buenos Aires, Ipesa, 1993.

Longoni, Ana. Vanguardia y Revolución. Arte e izquierdas en la Argentina de los sesenta-setenta. Buenos Aires, Ariel, 2014.

Lorena Verzero. Teatro militante: radicalización artística y política en los años 70. Buenos Aires, Biblos, 2013.

Luna, Félix. “Argentina Capital Buenos Aires”. Folklore, n 126, 1966, p. 7.

Manzano, Valeria. "Ha llegado la nueva ola. Música, consumo y juventud en la Argentina. 1955-1966”. Los '60 de otra manera. Vida cotidiana, género y sexualidades en la Argentina. Eds. Isabella Cosse,Karina Felitti y Valeria Manzano. Buenos Aires Prometeo, 2010, pp. 19-60.

---. "Making Third World Argentina: Place, Emotions and Revolutionary Politics, 1966-1976." $125^{\circ}$ Annual Meeting of the American Historical Association, Boston, 9 de enero de 2011. Ponencia.

---.The Age of Youth in Argentina. Culture, politics and sexuality from Perón To Videla. Chapel Hill, University of North Carolina Press, 2014.

---. "Rock Nacional and Revolutionary Politics: The Making of a Youth Culture of Contestation in Argentina”. The Americas, $n^{\circ}$ 70-3, 2014, pp. 393-427. 
---. "We Don't Want your Revolution: Conflicting Relations between Youth Countercultures and the New Left in Argentina, 1966-1976". American Historical Association $122^{\text {nd }}$ Annual Meeting, Washington DC, 6 de enero de 2008. Ponencia.

Marbiz, Julio. "Cosquín: Historia de un encuentro con el alma nacional". Folklore, ${ }^{\circ}$ 61, 1964, pp. 6-45.

Medovoi, Leerom, Rebels: Youth and the Cold War Origins of Identity. Durham, Duke University Press, 2005.

Mestman, Mariano. "Notas para una historia de un cine de contrainformación y lucha política”. Causas y Azares, n² 2, 1995, pp. 144-61.

Molinero, Carlos. Militancia de la canción. Política en el canto folklórico de la Argentina, 1944-1975. Buenos Aires, Ediciones de Aquí a la Vuelta, 2011.

Mudrovcic, María Eugenia. Mundo Nuevo. Cultura y Guerra fría en la década del sesenta. Buenos Aires, Beatriz Vitervo, 1997.

O’Donnell, Guillermo. El estado burocrático autoritario. Buenos Aires, Belgrano, 1996.

Ollier, María Matilde. De la revolución a la democracia: cambios privados, públicos y políticos de la izquierda argentina. Buenos Aires, Siglo XxI, 2009.

Pacini, Deborah, Eric Zolov y Héctor Fernández. Rockin' Las Américas: Rock Music Cultures Across Latin \& Latin/o America. Pittsburgh, University of Pittsburgh, 2004.

Petrus, Stephen y Ronald Cohen. Folk City. New York and the American Folk Music Revival. New York, Oxford University Press, 2015.

Podalsky, Laura. Specular City. Transforming Culture, Consumption, and Space in Buenos Aires, 1955-1973. Philadelphia, Temple University Press, 2004.

Policía de la Provincia de Buenos Aires, "Fiesta de la juventud en Lobos". Dirección Provincial por la Memoria, Legajo 15.557. Septiembre de 1970.

Pratt, Mary Louis. Ojos imperiales. Literatura de Viajes y transculturación. México, Fondo de Cultura Económica, 2010.

Pujó, Pedro. "Entrevista con Ana Sánchez Trolliet”. 11 agt. 2011. Inédito.

Pujol, Sergio, La historia del baile. De la milonga a la disco. Buenos Aires, Emecé, 1999.

---. Cien años de música argentina. Desde 1910 hasta nuestros días. Buenos Aires, Biblos, 2013.

---. La década rebelde. Los años 60 en Argentina. Buenos Aires, Emecé, 2002.

Rial Ungaro, Santiago. "Hombre de ningún lugar. La larga vida de Juan Carlos Kreimer”. Página 12. Suplemento Radar, 20 agt. 2016, https://www.pagina12.com. ar/diario/suplementos/radar/9-3187-2006-08-20.html

Ripoll, Daniel. “Bueno/malo”. Pelo, n¹, 1970, p. 1.

Sánchez Trolliet, Ana. "Buenos Aires Beat. A Topography of Rock Culture in Buenos Aires, 1965-1970". Urban History, n 41-3, 2014, pp. 517-36.

---. "Del sótano al estadio: transformaciones en los lugares de presentación de música rock en Buenos Aires, 1965-1970". Anales del Instituto de Arte Americano e Investigaciones Estéticas Mario J. Buschiazzo, n 44-2, 2014, pp. 175-90. 
Santoro, Rodolfo Claudio. "Se ponen en genios". Pelo, n6, 1970, p. 44.

---. “Correo de Lectores: El Trío Galleta la música complaciente”. Pelo, n4, 1970, p. 54. Schoo, Ernesto. "La nueva canción de los argentinos". Primera Plana, n² 286, 1968, p. 38. Schanton, Pablo "El rock como cultura. ¿Un proyecto inconcluso?”. Estéticas de la dispersión. Comp. Franco Ingrassia. Rosario, Beatriz Viterbo-Centro Cultural Parque de España, 2013, pp. 41-56.

Sottile, Antonieta. "La práctica de la cita en Alberto Ginastera”. Revista del ISM, 2016, pp. 131- 156.

Sorensen, Diana. A turbulent decade remembered. Scenes from the Latin American sixties. Stanford, Stanford University, 2007.

Spinetta, Luis Alberto. “Rock, música dura: la suicidada por la sociedad”. Rolanroc, $\mathrm{n}^{\circ} 1,1972$, p. 5 .

Strausbaugh, John. The Village. 400 Years of Beats and Bohemian, Radicals and Rogues. A History of Greenwich Village. Nueva York, Harper Collins, 2013.

Terán, Oscar. Nuestros años sesentas. La formación de la nueva izquierda intelectual argentina. Buenos Aires, Puntosur, 1991.

Tiro de Gracia. Dirigida por Ricardo Becher, producida por Guillermo Smith y Ricardo Becher, 1969.

Torre, Juan Carlos. "A partir del Cordobazo". Ensayos sobre movimiento obrero y peronismo. Buenos Aires, Siglo XXI, 2012.

Tortti, María Cristina. "Protesta Social y 'Nueva Izquierda' en la Argentina del Gran Acuerdo Nacional”. La primacía de la política: Lanusse, Perón y la nueva izquierda en tiempos del GaN. Ed.Alfredo Pucciarelli. Buenos Aires, Eudeba, 1999, pp. 205-30.

Urondo, Francisco. "El alma que canta, Cadícamo". Panorama, n 53, 1967, p. 96.

Villa, Javier. “Marta Minujín: a biography”. Marta Minujin. Obras 1959-1989. Buenos Aires, Malba-Fundación Costantini, 2010, pp. 267-303.

Viñas, David. De Sarmiento a Dios: viajeros argentinos a USA. Buenos Aires, Sudamericana, 1998.

Zolov, Eric "Introduction. Latin America in the Global Sixtiex". The Americas, ${ }^{\circ}$ 70-3, 2014, pp. 349-362.

--- "La onda chicana: Mexico’s Forgotten Rock Counterculture”. Rockin' Las Américas: Rock Music Cultures Across Latin \& Latin/o America. Ed. Deboran Pacini Hernández \& Héctor Fernández-L’Hoeste. Pittsburgh, University of Pittsburgh, 2004, pp. 22-42.

---. Refried Elvis. The Rise of the Mexican Counterculture. California, University of California, 1999. 